\title{
Clinical significance of random bladder biopsy in primary $\mathrm{T} 1$ bladder cancer
}

\author{
MASAFUMI OTSUKA $^{1}$, SATORU TAGUCHI ${ }^{1}$, TOHRU NAKAGAWA ${ }^{1}$, TEPPEI MORIKAWA ${ }^{2}$, \\ SHIGEKATSU MAEKAWA ${ }^{2}$, JIMPEI MIYAKAWA ${ }^{1}$, AKIHIKO MATSUMOTO ${ }^{1}$, HIDEYO MIYAZAKI ${ }^{1}$, \\ TETSUYA FUJIMURA ${ }^{1}$, HIROSHI FUKUHARA ${ }^{1}$, HARUKI KUME $^{1}$, YASUHIKO IGAWA ${ }^{3}$ and YUKIO HOMMA ${ }^{1}$ \\ Departments of ${ }^{1}$ Urology, ${ }^{2}$ Pathology and ${ }^{3}$ Continence Medicine, Graduate School of Medicine, \\ University of Tokyo, Tokyo 113-8655, Japan
}

Received November 7, 2017; Accepted February 27, 2018

DOI: $10.3892 / \mathrm{mco} .2018 .1587$

\begin{abstract}
The clinical significance of random bladder biopsies in primary non-muscle-invasive bladder cancer is unclear. The present study investigated the significance of positive random bladder biopsies in primary T1 NMIBC. The present study retrospectively reviewed the records of 71 patients with primary pT1N0M0 bladder cancer who underwent transurethral resection of the bladder tumor (TURBT) and concomitant random bladder biopsy. A total of 12 patients who received cystectomy immediately following the TURBT were excluded, and the remaining 59 patients were included in the analysis. Random bladder biopsy was defined as a cold-cup biopsy of pre-specified normal-looking areas in the bladder. The association of clinicopathological factors, including random biopsy results, with intravesical recurrence were assessed by univariate and multivariate Cox proportional hazards analyses. Of the 59 patients, 15 (25\%) demonstrated carcinoma in situ (CIS) lesions on random bladder biopsy: Five (33\%) in biopsy specimens alone and the remaining $10(67 \%)$ in biopsy and TUR specimens. Positive random biopsy was associated with preoperative positive urine cytology $(\mathrm{P}=0.011)$ and small size of the main tumor $(\mathrm{P}=0.008)$. Multivariate analysis demonstrated positive random biopsy as the sole independent poor prognostic factor for intravesical recurrence (hazard ratio: 4.69, $\mathrm{P}=0.014$ ). The five patients who had CIS detected in biopsy specimens alone had worse, although non-significantly worse, recurrence-free survival compared with those with CIS detected in biopsy and TUR specimens $(\mathrm{P}=0.100)$. In conclusion, positive bladder random biopsy, equivalent to the presence of CIS, was an independent predictor of recurrence in primary T1 bladder cancer. Given that one-third of CIS lesions could not have been detected
\end{abstract}

Correspondence to: Dr Tohru Nakagawa, Department of Urology, Graduate School of Medicine, University of Tokyo, 7-3-1 Hongo, Bunkyo-ku, Tokyo 113-8655, Japan

E-mail: tohru-tky@umin.ac.jp

Key words: bladder cancer, carcinoma in situ, random bladder biopsy, recurrence, non-muscle-invasive bladder cancer without biopsy, random bladder biopsy should be considered for patients with T1 tumors.

\section{Introduction}

Bladder cancer (BC) is the ninth most commonly diagnosed cancer in the world (1). Approximately $75 \%$ of cases are non-muscle invasive bladder cancer (NMIBC), including Ta, carcinoma in situ (CIS; Tis), and T1 tumors. NMIBC is associated with favorable cancer-specific survival compared to muscle invasive bladder cancer (MIBC) $(2,3)$. Among NMIBC, T1 tumor, which invades subepithelial connective tissue, has a high risk for recurrence and/or progression. Approximately one-third of T1 tumors develop recurrence and one-third eventually progress to MIBC $(4,5)$.

Bladders with T1 tumors may have CIS, which is a flat, high-grade, often multifocal, non-invasive urothelial carcinomatous lesion. Thus, random bladder biopsy, in which tissue is taken from the normal looking bladder mucosa, may be needed to detect CIS. CIS lesions are usually macroscopically indistinguishable from non-cancerous mucosa and can exist far away from the visible tumors. The European Association of Urology (EAU) guidelines recommend random bladder biopsy in patients with positive urine cytology (5). However, clinical significance of random bladder biopsy in primary NMIBC has not been fully evaluated. In this study, we investigated the significance of positive random bladder biopsy in primary T1 NMIBC.

\section{Patients and methods}

This study was approved by the Institutional Review Board of University of Tokyo Hospital (Tokyo, Japan; no. 3124). Written informed consent was obtained from each patient before surgery. We retrospectively reviewed medical records of 82 patients with primary pT1N0M0 bladder cancer who underwent transurethral resection of the bladder tumor (TURBT) at The University of Tokyo Hospital between January 2007 and December 2014. Amongst these 82 patients, random bladder biopsy was performed along with TURBT in 71 patients. After excluding 12 patients who received radical cystectomy immediately (within 3 months) after the initial TURBT, we 
included the remaining 59 patients in the present study cohort (Fig. 1).

Random bladder biopsy was defined as cold-cup biopsy of normal-looking tissues. Although this biopsy is designated as 'random', the biopsy samples were systematically obtained from eight pre-specified areas: The bladder trigone, right wall, left wall, posterior wall, dome, anterior wall, bladder neck, and prostatic urethra of both sides. The urethra was not sampled in female patients. Biopsy targeting suspicious (i.e. reddish) tissues was not regarded as random biopsy. All biopsy specimens were reviewed by a single pathologist (T.M.). Histological diagnosis was performed according to the World Health Organization (WHO) 2016 classification system (6).

Pirarubicin (THP) $20 \mathrm{mg}$ was routinely instilled immediately after TURBT as intravesical chemotherapy. A second TURBT was carried out for T1 bladder tumors, if the specimen lacked adequate muscle layer for histological examination. Bacillus Calmette-Guerin (BCG) instillation for 6 to 8 consecutive weeks of Immunobladder ${ }^{\circledR}$ (Tokyo 172 strain) or ImmuCyst ${ }^{\circledR}$ (Connaught strain) was indicated. However, the attending physician and/or patient sometimes decided against BCG because of the risk of side effects. Post-surgical follow-up constituted cystoscopy and urine cytology, every 3 months for the first 2 years, then every 6 months until 5 years, and annually thereafter.

The primary endpoint was recurrence-free survival (RFS). Recurrence was defined as histologically proven intravesical recurrence. The secondary endpoint was progression-free survival (PFS). Progression was defined as appearance of MIBC and/or nodal or distant metastasis. Recurrence-free interval and progression-free interval were defined as the time from TURBT to recurrence or progression.

The correlation of the random biopsy result with age was evaluated using Mann-Whitney U test, and the correlation with sex, urine cytology, grade, concomitant CIS, multifocality, tumor size, intravesical chemotherapy, and BCG instillation was evaluated using Pearson's chi-square test.

RFS and PFS were estimated by the Kaplan-Meier method and compared using the Log-rank test. For multivariate analysis, Cox's proportional hazards regression model was used with a backward stepwise procedure (entry, 0.05; removal, 0.10). All statistical analyses were performed using $\mathrm{JMP}^{\circledR}$ 11 (SAS Institute Inc., Cary, NC, USA). Probability P-values $<0.05$ were considered statistically significant.

\section{Results}

The study cohort comprised 48 males and 11 females, with a median age of 74 years [interquartile range (IQR), 64-81 years]. CIS lesions were detected in random biopsy samples in 15 (25\%) patients (Table I). Positive random biopsy completely overlapped with concomitant CIS, and was significantly correlated with positive cytology $(\mathrm{P}=0.011)$ and main tumor size less than $3 \mathrm{~cm}(\mathrm{P}=0.008)$.

During the median follow-up of 32 months (IQR, 18-51 months), 15 (25\%) patients had recurrence at a median time of 24 months (IQR, 12.5-41.5 months), and five (8\%) patients developed progression at a median time of 31 months (IQR, 16.5-49.5 months).

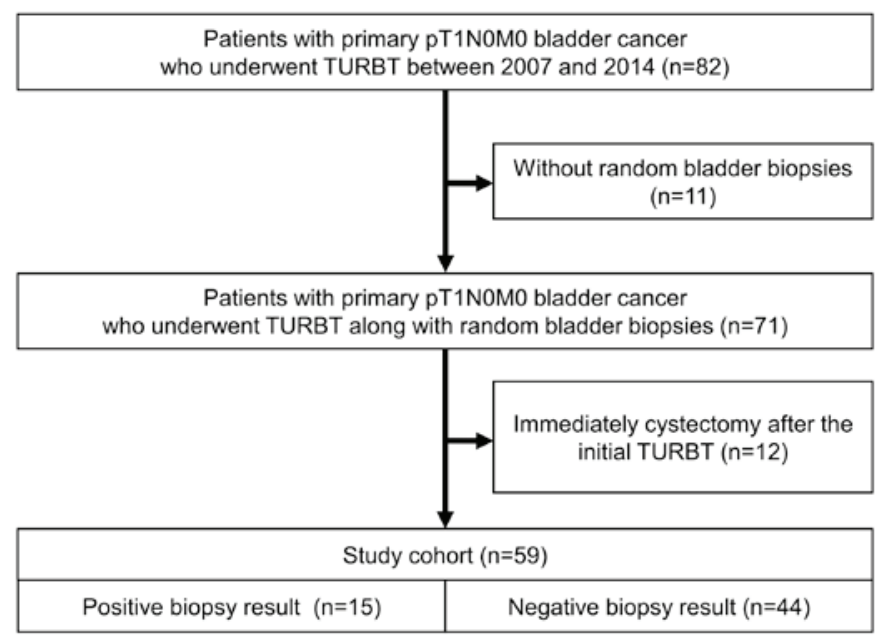

Figure 1. The study cohort.

The estimated RFS rate at 3 years in patients with positive random biopsy (67\%) was significantly lower than that in patients with negative biopsy $(81 \%)(\mathrm{P}=0.025$, Fig. $2 \mathrm{~A})$; so was the PFS rate at 3 years (66\% for positive biopsy and $97 \%$ for negative biopsy, respectively; $\mathrm{P}=0.006$, Fig. $2 \mathrm{~B}$ ). Risk factors that were analyzed in the study included patient age ( $<74$ vs. $\geq 74$ years), sex, urine cytology (negative vs. positive), random biopsy result (negative vs. positive), tumor grade (low vs. high), multifocality, tumor size ( $<3$ vs. $\geq 3 \mathrm{~cm}$ ), intravesical chemotherapy, and BCG instillation (Table II). On the multivariate analysis, positive random biopsy was found to be an independent poor prognostic factor for recurrence $(\mathrm{P}=0.014$, hazard ratio $=4.69,95 \%$ confidence interval $1.40-15.4)$. Although positive random biopsy results were also associated with poor PFS ( $\mathrm{P}=0.006$, Fig. 2B), multivariate analysis for PFS could not be performed because of infrequent events $(n=5)$.

When the 15 patients with positive random biopsy were divided into those with positive results at biopsy sites alone $(n=5)$ and those with positive results at both biopsy sites and adjacent to visible tumors of TUR samples $(n=10)$, the former showed non-significantly lower RFS and PFS than the latter $(\mathrm{P}=0.100, \mathrm{P}=0.327$, respectively; Fig. 3 ). The former five patients had significantly lower RFS and PFS than those without CIS $(\mathrm{P}=0.002$ and $\mathrm{P}=0.011$, respectively), while the latter 10 patients had non-significantly lower RFS and significantly lower PFS than those without CIS ( $\mathrm{P}=0.248$ and $\mathrm{P}=0.024$, respectively).

\section{Discussion}

In the present study, CIS was detected by random bladder biopsy in $25 \%$ of the patients with primary pT1 bladder cancer. The presence of CIS in one-third of these patients could not have been proved without random biopsy. Positive result at random biopsy, equivalent to the presence of CIS, was an independent predictor of recurrence.

The EAU guidelines recommend that all suspicious areas in the bladder should be biopsied. On the other hand, random bladder biopsies are not recommended for all patients with NMIBC but only for the patients with positive urine cytology or with high-risk non-papillary exophytic tumors (5). Bladder 
Table I. Patient characteristics.

\begin{tabular}{|c|c|c|c|c|}
\hline \multirow[b]{2}{*}{ Variables } & \multirow[b]{2}{*}{ Total $(n=59)$} & \multicolumn{2}{|c|}{ Random bladder biopsy } & \multirow[b]{2}{*}{ P-value } \\
\hline & & Positive $(n=15)$ & Negative $(n=44)$ & \\
\hline Age, years, median (IQR) & $74(64-81)$ & $79(69-84)$ & $72(64-79)$ & $0.2161^{\mathrm{a}}$ \\
\hline Sex & & & & $0.8766^{\mathrm{b}}$ \\
\hline Male & $48(81 \%)$ & $12(80 \%)$ & $36(82 \%)$ & \\
\hline Female & $11(19 \%)$ & $3(20 \%)$ & $8(18 \%)$ & \\
\hline Urine cytology & & & & $0.0111^{\mathrm{b}, \mathrm{c}}$ \\
\hline Negative & $28(47 \%)$ & $3(20 \%)$ & $25(57 \%)$ & \\
\hline Positive & $31(53 \%)$ & $12(80 \%)$ & $19(43 \%)$ & \\
\hline Grade & & & & $0.0789^{\mathrm{b}}$ \\
\hline Low & $5(8 \%)$ & $0(0 \%)$ & $5(11 \%)$ & \\
\hline High & $54(92 \%)$ & $15(100 \%)$ & $39(89 \%)$ & \\
\hline Concomitant CIS & & & & $<0.0001^{\mathrm{b}, \mathrm{c}}$ \\
\hline Negative & $44(75 \%)$ & $0(0 \%)$ & $44(100 \%)$ & \\
\hline Positive & $15(25 \%)$ & $15(100 \%)$ & $0(0 \%)$ & \\
\hline Multifocality & & & & $0.7076^{\mathrm{b}}$ \\
\hline Solitary & $30(51 \%)$ & $7(47 \%)$ & $23(52 \%)$ & \\
\hline Multiple & $29(49 \%)$ & $8(53 \%)$ & $21(48 \%)$ & \\
\hline Tumor size, $\mathrm{cm}$ & & & & $0.0084^{\mathrm{b}, \mathrm{c}}$ \\
\hline$<3$ & $35(59 \%)$ & $13(87 \%)$ & $22(50 \%)$ & \\
\hline$\geq 3$ & $24(41 \%)$ & $2(13 \%)$ & $22(50 \%)$ & \\
\hline 2nd TURBT & & & & $0.6798^{\mathrm{b}}$ \\
\hline No & $21(36 \%)$ & $6(40 \%)$ & $15(34 \%)$ & \\
\hline Yes & $38(64 \%)$ & $9(60 \%)$ & $29(66 \%)$ & \\
\hline Instillation of intravesical chemotherapy & & & & $0.7076^{\mathrm{b}}$ \\
\hline No & $29(49 \%)$ & $8(53 \%)$ & $21(48 \%)$ & \\
\hline Yes & $30(51 \%)$ & $7(47 \%)$ & $23(52 \%)$ & \\
\hline BCG instillation & & & & $0.0555^{\mathrm{b}}$ \\
\hline No & $19(32 \%)$ & $2(13 \%)$ & $17(39 \%)$ & \\
\hline Yes & $40(68 \%)$ & $13(87 \%)$ & $27(61 \%)$ & \\
\hline
\end{tabular}

IQR, interquartile range; CIS, carcinoma in situ; Instillation of intravesical chemotherapy, single immediate post-operative intravesical chemotherapy; BCG, Bacillus Calmette-Guérin; ${ }^{a}$ Mann-Whitney U test; ${ }^{b}$ Pearson's chi-square test. ${ }^{\text {s }}$ statistically significant.

biopsy carries risks of bleeding, infection, and even the possible implantation of tumor cells at the biopsied mucosa (7). Thus, the indications of random bladder biopsies needs to be carefully optimized. Previous studies have reported that random bladder biopsy has demonstrated positive results in 5 to $30 \%$ of the patients with all-risk NMIBC, and in as high as $60 \%$ of the patients with high-risk NMIBC (8-12). However, prognostic significance of random bladder biopsy in primary NMIBC has not been well defined.

In this study, $15(25 \%)$ of the 59 patients demonstrated carcinomatous lesions by random bladder biopsy, all of which were CIS. Conversely, all 15 cases with CIS were positive on random biopsy. In more detail, five (33\%) patients had CIS only in biopsy specimens, whereas the remaining $10(67 \%)$ had CIS in both biopsy and TUR specimens. The existence of CIS, equivalent to positive random biopsy result, was shown to be an independent poor prognostic factor for recurrence and was associated with disease progression in univariate analysis.
Although these results are in line with previous reports assessing the prognostic significance of CIS (13), it should be noted that one-third of CIS lesions could not have been detected without random bladder biopsy. Moreover, patients who yielded positive results only in biopsy specimens had worse RFS and PFS than the remaining two-third patients who yielded positive results in both biopsy and TUR specimens; however, the differences were not statistically significant. Our results suggested that random bladder biopsy might be justified for patients with $\mathrm{T} 1$ tumors.

T1 NMIBC generally carries high risk of recurrence and progression. Early cystectomy should be considered for carefully selected patients with T1 NMIBC (14). Several studies have identified potential prognostic factors in T1 NMIBC, including sex, age, tumor diameter, CIS, tumor grade, multifocality, lymphovascular invasion, lamina propria invasion, solid tumor pattern, and immunohistochemical detection of p53 in the tumor-cell nuclei $(13,15-20)$. However, optimal 
A

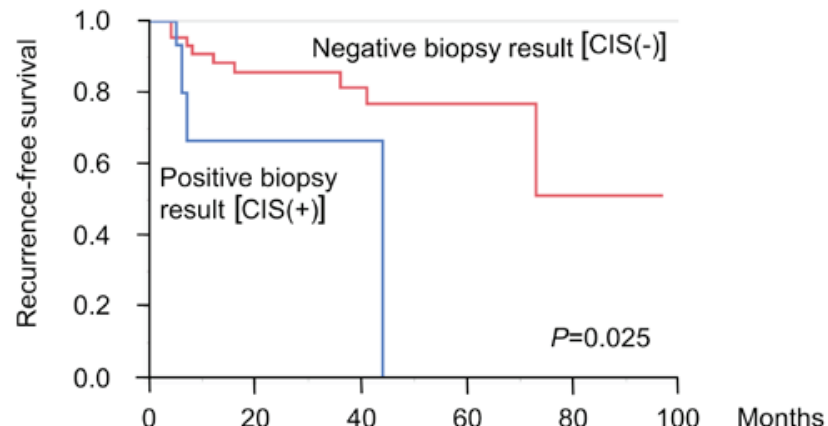

$\begin{array}{ccccccc}\text { Number at risk: } & & & & & & \\ \text { Negative biopsy result [CIS }(-)] & 44 & 27 & 18 & 8 & 2 & 1 \\ \text { Positive biopsy result [CIS }(+)] & 15 & 7 & 1 & 0 & 0 & 0\end{array}$

B

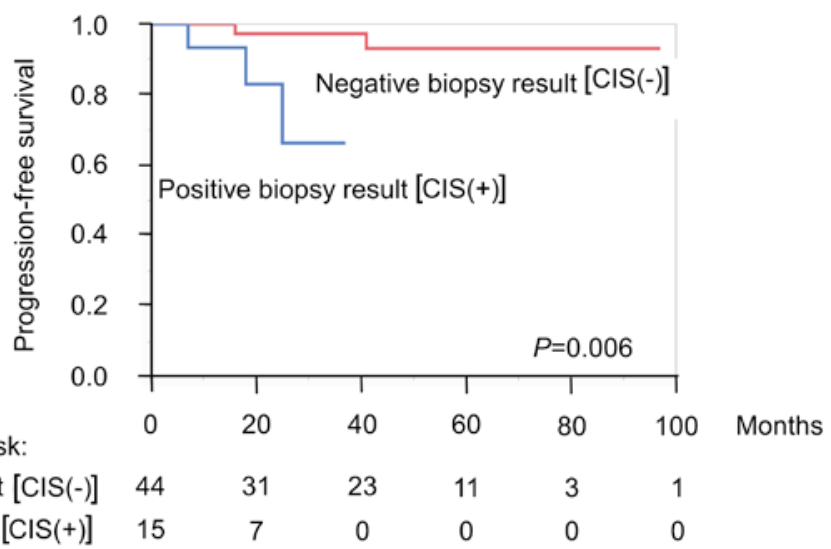

Figure 2. (A) Kaplan-Meier estimates for recurrence-free survival stratified by the random bladder biopsy result (positive vs. negative, $\mathrm{P}=0.025$, log-rank test). (B) Kaplan-Meier estimates for progression-free survival stratified by the random bladder biopsy result (positive vs. negative, $\mathrm{P}=0.006, \mathrm{log}$-rank test).

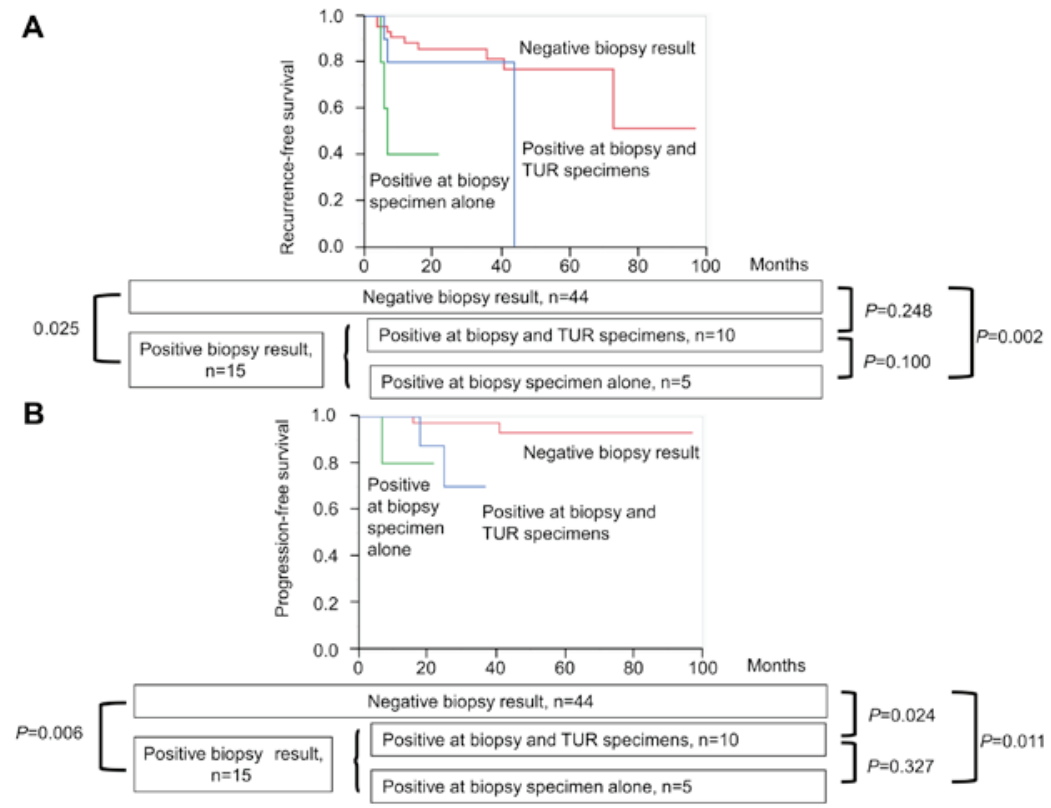

Figure 3. (A) Kaplan-Meier estimates for (A) recurrence-free and (B) progression-free survivals stratified by CIS [CIS(-) vs. CIS(+) at both visible tumors and random biopsy vs. CIS(+) at random biopsy alone].

prediction of recurrence and progression of tumor is still under debate. Our results have provided a rationale for the precise detection of CIS by random bladder biopsy.

The formation of tumors in multiple foci throughout the entire urinary tract is one of the most important features of urothelial cancer. CIS is a flat, intraurothelial neoplasm and believed to be a precursor of invasive bladder cancer. The detection of CIS was traditionally performed with combination of urine cytology, cystoscopy, and random bladder biopsy. Although experienced urologists may be able to point 
Table II. Univariate and multivariate analyses of risk factors for recurrence.

\begin{tabular}{|c|c|c|c|c|}
\hline \multirow[b]{2}{*}{ Factor } & \multicolumn{2}{|c|}{ Univariate } & \multicolumn{2}{|c|}{ Multivariate } \\
\hline & HR (95\% CI) & P-value & $\mathrm{HR}(95 \% \mathrm{CI})$ & P-value \\
\hline Age, years & & 0.1219 & & \\
\hline$<74$ & Reference & & & \\
\hline$\geq 74$ & $2.30(0.80-7.46)$ & & & \\
\hline Sex & & 0.4524 & & \\
\hline Male & Reference & & & \\
\hline Female & $1.58(0.44-4.66)$ & & & \\
\hline Urine cytology & & 0.9563 & & \\
\hline Negative & Reference & & & \\
\hline Positive & $1.03(0.35-3.03)$ & & & \\
\hline Random biopsy result & & $0.0431^{\mathrm{a}}$ & & $0.0136^{\mathrm{a}}$ \\
\hline Negative & Reference & & Reference & \\
\hline Positive & $3.25(1.04-9.72)$ & & $4.69(1.40-15.4)$ & \\
\hline Grade & & 0.8007 & & \\
\hline Low & Reference & & & \\
\hline High & $1.29(0.25-23.5)$ & & & \\
\hline Multifocality & & 0.8708 & & \\
\hline Solitary & Reference & & & \\
\hline Multiple & $1.09(0.37-3.20)$ & & & \\
\hline Tumor size & & 0.8698 & & \\
\hline$<3 \mathrm{~cm}$ & Reference & & & \\
\hline$\geq 3 \mathrm{~cm}$ & $0.92(0.31-2.56)$ & & & \\
\hline Instillation of intravesical chemotherapy & & 0.0756 & & \\
\hline No & Reference & & & \\
\hline Yes & $0.37(0.10-1.11)$ & & & \\
\hline BCG instillation & & 0.1896 & & 0.0536 \\
\hline No & Reference & & Reference & \\
\hline Yes & $0.49(0.17-1.44)$ & & $0.32(0.10-1.02)$ & \\
\hline
\end{tabular}

HR, hazard ratio; CI, confidence interval; CIS, carcinoma in situ; Instillation of intravesical chemotherapy, single immediate post-operative

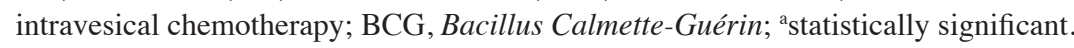

out possible CIS areas on cystoscopy, these lesions may be overlooked without random bladder biopsy. Recent advances in fluorescence cystoscopy and narrow-band imaging may aid in detecting flat CIS lesions, and their results need to be compared with those of random bladder biopsy $(21,22)$.

The present study has several limitations. This is a retrospective analysis of a relatively small study cohort at a single center. Treatment scheme including second TUR and BCG administration had not been standardized. There were only 5 patients with positive results in biopsy specimens alone, and only 5 of 59 patients developed progression. Despite that the differences were statistically significant and that their implications were clinically meaningful, the results need to be interpreted cautiously. Thus, a large-scale multicenter study would be necessary to validate the findings of our study.

In conclusion, Positive bladder random biopsy, equivalent to the presence of CIS, was an independent predictor of recurrence in primary $\mathrm{T} 1$ bladder cancer. Only $11 \%$ of the patients with negative urine cytology had CIS, and therefore the results of random biopsy affect only limited fraction of patients. However, given that one-third of CIS lesions could not have been detected without biopsy, random bladder biopsy may be considered for patients with T1 tumors.

\section{Acknowledgements}

The authors would like to thank all staff in the Department of Urology of the University of Tokyo for their help and support.

\section{Funding}

No funding was received.

\section{Availability of data and materials}

The datasets analyzed during the current study are not publicly available due to the regulations of the Institutional Review Board (IRB) of University of Tokyo Hospital, however are 
available from the corresponding author on reasonable request and after approval by IRB.

\section{Authors' contributions}

MO, ST, TN, conception and design. MO, ST, TM, SM, JM, acquisition of data. MO, ST, TN, TM, SM, JM, AM, HM, TF, $\mathrm{HF}, \mathrm{HK}, \mathrm{YI}, \mathrm{YH}$, analysis and interpretation of data, final approval of the version to be published, sufficient participation in the work to take public responsibility for appropriate portions of the content and have agreed to be accountable for all aspects of the work in ensuring that questions related to the accuracy or integrity of any part of the work are appropriately investigated and resolved.

MO and TN, drafting of the manuscript. ST, TM, SM, JM, AM, HM, TF, HF, HK, YI, YH, critical revision of the manuscript for important intellectual content. YI also contributed administrative support and $\mathrm{YH}$ as supervisor.

\section{Ethics approval and consent to participate}

The present study was approved by the Institutional Review Board of University of Tokyo Hospital (Tokyo, Japan; no. 3124). Written informed consent was obtained from each patient prior to surgery.

\section{Consent for publication}

Written informed consent was obtained from each patient prior to surgery.

\section{Competing interests}

The authors declare that they have no competing interests.

\section{References}

1. Ferlay J, Shin HR, Bray F, Forman D, Mathers C and Parkin DM: Estimates of worldwide burden of cancer in 2008: GLOBOCAN 2008. Int J Cancer 127: 2893-2917, 2010.

2. Burger M, Catto JW, Dalbagni G, Grossman HB, Herr H, Karakiewicz P, Kassouf W, Kiemeney LA, La Vecchia C, Shariat S and Lotan Y: Epidemiology and risk factors of urothelial bladder cancer. Eur Urol 63: 234-241, 2013.

3. Steinmaus C, Ferreccio C, Acevedo J, Yuan Y, Liaw J, Durán V, Cuevas S, García J, Meza R, Valdés R, et al: Increased lung and bladder cancer incidence in adults after in utero and early-life arsenic exposure. Cancer Epidemiol Biomarkers Prev 23: 1529-1538, 2014

4. Van Rhijn BW, Burger M, Lotan Y, Solsona E, Stief CG, Sylvester RJ, Witjes JA and Zlotta AR: Recurrence and progression of disease in non-muscle invasive bladder cancer: From epidemiology to treatment strategy. Eur Urol 56: 430-442, 2009.

5. Babjuk M, Burger M, Zigeuner R, Shariat SF, van Rhijn BW, Compérat E, Sylvester RJ, Kaasinen E, Böhle A, Palou Redorta J, et al: EAU guidelines on non-muscle-invasive urothelial carcinoma of the bladder: update 2013. Eur Urol 64: 639-653, 2013.

6. Moch H, Cubilla AL, Humphrey PA, Reuter VE and Ulbright TM The 2016 WHO Classification of Tumours of the urinary system and male genital organs-part A: Renal, penile, and testicular tumours. Eur Urol 70: 93-105, 2016.

7. Soloway MS and Masters S: Urothelial susceptibility to tumor cell implantation. Influence of cauterization. Cancer 46 1158-1163, 1980.
8. Fradet Y, Grossman HB, Gomella L, Lerner S, Cookson M, Albala D and Droller MJ; PC B302/01 Study Group: PC B302/01 study group. A comparison of hexaminolevulinate fluorescence cystoscopy and white light cystoscopy for the detection of carcinoma in situ in patients with bladder cancer: A phase III, multicenter study. J Urol 178: 68-73, 2007.

9. May F, Treiber U, Hartung R and Schwaibold H: Significance of random bladder biopsies in superficial bladder cancer. Eur Urol 44: 47-50, 2003.

10. Taguchi I, Gohji K, Hara I, Gotoh A, Yamada Y, Yamanaka K, Okada H, Arakawa S and Kamidono S: Clinical evaluation of random biopsy of urinary bladder in patients with superficial bladder cancer. Int J Urol 5: 30-34, 1998.

11. Fujimoto N, Harada S, Terado M, Sato H and Matsumoto T: Multiple biopsies of normal-looking urothelium in patients with superficial bladder cancer: Are they necessary? Int J Urol 10: 631-635, 2003.

12. Hara T, Takahashi M, Gondo T, Nagao K, Ohmi C, Sakano S, Naito $\mathrm{K}$ and Matsuyama H: Risk of concomitant carcinoma in situ determining biopsy candidates among primary non-muscle-invasive bladder cancer patients: Retrospective analysis of 173 Japanese cases. Int J Urol 16: 293-298, 2009.

13. Denzinger S, Otto W, Fritsche HM, Roessler W, Wieland WF, Hartmann A and Burger M: Bladder sparing approach for initial T1G3 bladder cancer: Do multifocality, size of tumor or concomitant carcinoma in situ matter? A long-term analysis of 132 patients. Int J Urol 14: 995-999, 2007.

14. Herr HW and Sogani PC: Does early cystectomy improve the survival of patients with high risk superficial bladder tumors? J Urol 166: 1296-1299, 2001.

15. Palou J, Sylvester RJ, Faba OR, Parada R, Peña JA, Algaba F and Villavicencio $\mathrm{H}$ : Female gender and carcinoma in situ in the prostatic urethra are prognostic factors for recurrence, progression and disease-specific mortality in T1G3 bladder cancer patients treated with Bacillus Calmette-Guérin. Eur Urol 62: 118-125, 2012.

16. Fernandez-Gomez J, Solsona E, Unda M, Martinez-Piñeiro L, Gonzalez M, Hernandez R, Madero R, Ojea A, Pertusa C, Rodriguez-Molina J, et al: Club Urológico Español de Tratamiento Oncológico CUETO). Prognostic factors in patients with non-muscle-invasive bladder cancer treated with Bacillus Calmette-Guérin: Multivariate analysis of data from four randomized CUETO trials. Eur Urol 53: 992-1001, 2008.

17. Fukumoto K, Kikuchi E, Mikami S, Miyajima A and Oya M: Lymphovascular invasion status at transurethral resection of bladder tumors may predict subsequent poor response of T1 tumors to Bacillus Calmette-Guérin. BMC Urol 16: 5, 2016.

18. Orsola A, Trias I, Raventos CX, Español I, Cecchini L, Búcar S, Salinas D and Orsola I: Initial high-grade T1 urothelial cell carcinoma: Feasibility and prognostic significance of lamina propria invasion microstaging $(\mathrm{T} 1 \mathrm{a} / \mathrm{b} / \mathrm{c})$ in $\mathrm{BCG}$-treated and BCG-non-treated patients. Eur Urol 48: 231-238, 2005.

19. Andius P, Johansson SL and Holmang S: Prognostic factors in stage T1 bladder cancer: Tumor pattern (solid or papillary) and vascular invasion more important than depth of invasion. Urology 70: 758-762, 2007.

20. Esrig D, Elmajian D, Groshen S, Freeman JA, Stein JP, Chen SC, Nichols PW, Skinner DG, Jones PA and Cote RJ: Accumulation of nuclear p53 and tumor progression in bladder cancer. N Engl J Med 331: 1259-1264, 1994

21. Drejer D, Béji S, Oezeke R, Nielsen AM, Høyer S, Bjerklund Johansen TE, Lam GW and Jensen JB: Comparison of white light, photodynamic diagnosis and narrow-band imaging in detection of carcinoma in situ or flat dysplasia at transurethral resection of the bladder: The DaBlaCa-8 study. Urology 102: 138-142, 2017.

22. Schmidbauer J, Witjes F, Schmeller N, Donat R, Susani M and Marberger M: Hexvix PCB301/01 study group: Improved detection of urothelial carcinoma in situ with hexaminolevulinate fluorescence cystoscopy. J Urol 171: 135-138, 2004. 